\title{
Coulisses
}

Revue de théâtre

5 | Hiver 1992

Varia

\section{La Cantatrice chauve}

Philippe Blondeau

\section{(2) OpenEdition}

Journals

Édition électronique

URL : http://journals.openedition.org/coulisses/1703

DOI : $10.4000 /$ coulisses. 1703

ISSN : 2546-9460

\section{Éditeur}

Presses universitaires de Franche-Comté

\section{Édition imprimée}

Date de publication : 1 janvier 1992

Pagination : $6-9$

ISSN : 1150-594X

\section{Référence électronique}

Philippe Blondeau, «La Cantatrice chauve », Coulisses [En ligne], 5 | Hiver 1992, mis en ligne le 04 juillet 2017, consulté le 22 octobre 2019. URL : http://journals.openedition.org/coulisses/1703 ; DOI :

10.4000/coulisses.1703

Ce document a été généré automatiquement le 22 octobre 2019

Coulisses 


\section{La Cantatrice chauve}

\section{Philippe Blondeau}

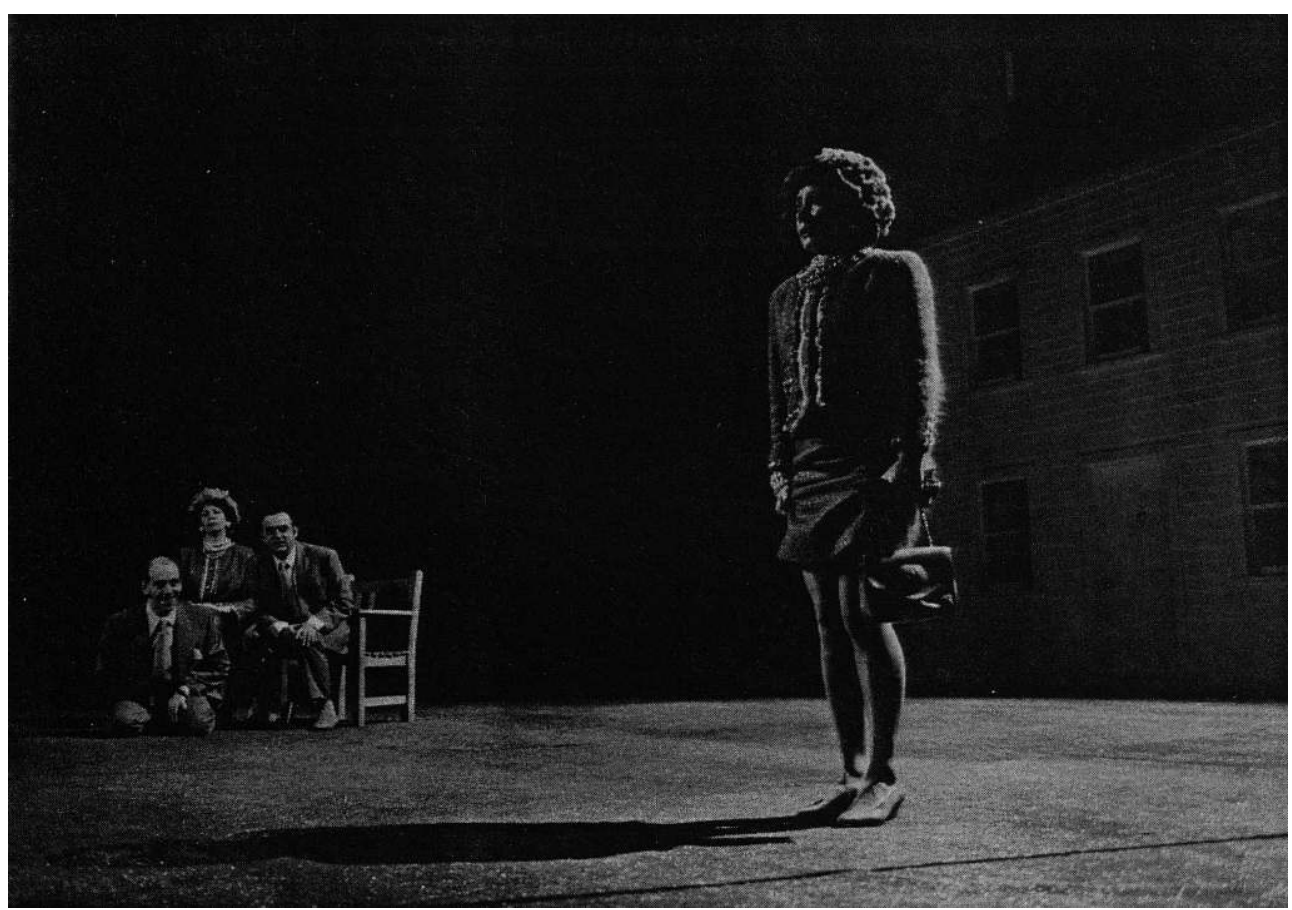

La Cantatrice chauve : photo Quenneville, Paris.

\section{Une mise en scène filmique}

1 La mise en scène de J.-L. Lagarce évoque de façon sensible le dessin animé. Le décor semble issu d'un dessin d'enfant avec des couleurs naïves, un peu acidulées (rose bonbon, vert pomme, jaune fluo...) et une façade de maison telle que l'imaginaire enfantin pourrait se la représenter. Sur scène se créé un réseau dynamique de significations : un songe, par certains aspects, notamment par le choix des couleurs, à Walt Disney, Madame Smith et madame Martin évoquent quant à elles Mary Poppins et 
son univers étrange qui s'intègre bien dans la pièce de Ionesco, tandis que Monsieur Smith et Monsieur Martin rappellent Laurel et Hardy, permettant d'enrichir la mise en scène de références implicites au film muet du début du siècle (on songe à Chaplin lorsqu'on voit les personnages adopter des démarches désarticulées ; à la fin, le décor qui s'écroule est une idée prise chez Buster Keaton).

2 Lagarce utilise le dessin animé et le film muet pour faire sentir de façon plus pénétrante le sentiment d'étrangeté au monde qui est central dans la pièce de Ionesco : ces personnages projetés dans le dessin animé, monde insolite et dérangeant, réveillent chez le spectateur certaines angoisses profondes : sentiment de claustration dans cette prison de l'enfance (le décor joue habilement sur l'ambiguïté intérieur/extérieur), terreur de la régression infantile et d'une immobilité du temps qui figerait adultes et enfants dans la même sphère close.

3 La pièce de Ionesco intègre avec bonheur ce parti-pris du metteur en scène d'utiliser certains éléments naïfs, d'autant plus que le dramaturge roumain était lui même passionné par Guignol et le théâtre de marionnettes, influencé en cela par Jarry et son cycle des Ubu.

\section{Un regard parodique}

4 La mise en scène de Lagarce joue volontiers avec la parodie des genres que propose le texte de Ionesco : à la scène IX, c'est le mélo qui est tourné en dérision, l'innocence amoureuse de la bonne est honteusement persécutée par les "bourgeois sans cœur ». La pièce de Ionesco utilise de façon dynamique des procédés de décalage : l'émotion des personnages est démesurée face à l'événement (ou le non-événement) qui la suscite. L'émotion intense des personnages répond au vide d'une situation dérisoire. Lagarce intègre de façon subtile ce procédé textuel dans sa mise en scène: la musique de «Psychose » est utilisée lorsque madame Smith va ouvrir la porte au pompier, créant un effet musical de suspens, insoutenable, dans une situation quotidienne, banale, sans relief. De plus, cet effet permet au metteur en scène d'enrichir la veine parodique de $L a$ cantatrice chauve en ajoutant une allusion ironique, en forme de clin d'œil, au film à suspens. "Tragédie du langage", la pièce de Ionesco s'approprie et renverse les mécanismes de la tragédie, précisément parce que Dieu (la fatalité) n'est pas là pour permettre la progression dynamique des personnages et de l'action jusqu'au dénouement final. Ici, le temps cyclique, (bien mis en évidence par Lagarce), est celui $\mathrm{du}$ vide qui tourne en rond, rien ne se passe, tout recommence, aucun dénouement n'est possible puisqu'il n'y a rien à dénouer. La scène tragique de la reconnaissance, qui doit allier « vraisemblance et pathétique » pour Aristote met ici aux prises monsieur et madame Martin dans une confrontation où l'invraisemblance crée le comique. Dans un époustouflant délire verbal, les personnages se libèrent de tous ces mots qui les obsèdent. Les signes explosent, expulsés dans un effet de crescendo à la fois hilarant et terriblement libérateur pour le spectateur (curieusement, l'anti-catharsis de Ionesco est sans doute plus efficace que la vraie. Une lecture Freudienne montrerait que c'est dans le mot que la pulsion s'incarne pour aussitôt s'annihiler, l'inconscient étant le lieu du non-langage). Le langage prend la place d'un Dieu absent, dans la mise en scène de Lagarce : lorsqu'il raconte une histoire insensée de rhume, le personnage du pompier, monté sur une chaise se métamorphose en figure christique: les bras en croix, le casque illuminé par une lueur céleste tandis qu'une couronne d'épine est esquissée par 
un habile jeu de lumière, il est le messie absurde, le messie du non- sens. «Au début était le verbe » dit la Bible : ici, l'effet est radicalement parodique, comique. Ce pompier verbeux dispense comme une anti-hostie son « soulas sémantique " (Beckett), ces mots sans queue ni tête qui font comme une drogue, oublier un instant le vide.

\section{La dérision}

5 Tous les personnages participent ici de la mise en dérision des genres, jusqu'à la bonne qui, par ses adresses répétées au public semble un peu hors scène, personnage ambigu qui s'intègre parfois mal dans la mise en scène: faut-il voir en elle une antireprésentation du chœur antique? Une lecture Hégélienne la ferait apparaitre comme l'esclave qui, parce que ses maîtres sont devenus des incapables, finit par les dominer, dans un jeu de renversement dialectique. La mise-en-scène de Lagarce qui fait de la bonne un personnage un peu tyrannique, craint par ses employeurs, s'intégrerait bien dans cette perspective. Mais la bonne est peut- être avant tout celle qui fait de l'antipièce de Ionesco une meta- pièce en dispensant tout au long du spectacle des indications purement théâtrales sur la mise en scène : elle est sans nul doute l'envoyée de Brecht, celle qui instaure sans cesse un effet de distance entre le spectacle et la scène. Évidemment, le très anti-brechtien Ionesco ne se prive pas, à travers la mise en scène de Lagarce, de tourner en ridicule la théorie de la distanciation, et le metteur en scène en rajoute en utilisant un système de rires enregistrés, qui n'est pourtant pas toujours du meilleur effet. Parodie encore lorsque, à la fin de la pièce, les acteurs proposent d'insulter le public, de le mitrailler, et l'invitent à envahir la scène : le public ne bouge pas et Ionesco peut se féliciter d'avoir empiriquement réduit à néant la théorie d'Artaud et son théâtre de la cruauté.

Lagarce fait encore bien sentir (trop bien?) que Ionesco n'est pas dupe de l'illusion théâtrale et que La Cantatrice chauve contient, en germe, une mise à plat du théâtre et de ses " grosses ficelles » (Ionesco) : lorsque le décor s'écroule, les acteurs se retrouvent un peu hébétés, entre illusion et réalité. Le procédé est habile: le décor qui tombe démasque le théâtre comme temple de l'illusion, ceci permet de glisser vers un retour au réel et d'amorcer, une fois le subterfuge dénoncé, un dialogue avec le public, sous les projecteurs rallumés de la pleine réalité.

\section{Un absurde dynamique}

7 Parce que la pièce remet sans cesse en cause les mécanismes du spectacle théâtral, elle est dans un état de perpétuelle instabilité, d'une certaine façon d'auto-destruction: meta-pièce, elle détruit à chaque instant l'illusion scénique. Mais la visée ne peut être gratuite ou simplement parodique : en refusant de cautionner l'illusion, par un effet de renversement, c'est la substance même de la vie qui est jetée sur scène, la quintessence de la condition humaine et le combat tragique de l'homme et du langage. L'illusion détruite, il reste la vie, la force brute et dérangeante de la pure réalité.

8 Car la pièce de Ionesco est terriblement réaliste et joue sur des effets de grossissement : la mise en scène de Lagarce perd peut- être en puissance parce qu'en cherchant parfois à faire rire gratuitement, elle tourne à vide dans des effets clownesques inutiles (la démarche ridicule de madame Smith quand elle va ouvrir la porte). Il faut sans doute 
que la mise en scène s'efforce de préserver cette tension propre à Ionesco, cette hésitation de chaque instant entre les rires et les pleurs, cet état d'équilibre instable et dynamique. Toutefois, même si l'on peut préférer une mise en scène plus stylisée, une mise en scène « en creux » faisant rebondir sur une scène épurée de tout effet inutile, des mots vides, livrés à eux mêmes et résonant dans la pureté du non-sens, si l'on peut regretter qu'une certaine surabondance scénique s'accorde mal avec la problématique de l'absurde, la nausée, le rien, l'absence, il faut bien avouer que le spectacle de J.L. Lagarce, en exploitant la veine parodique, réactualise de façon dynamique une antipièce qui mérite de ne pas devenir un « classique ». 